\title{
Hereditåres Mammakarzinom: BRCA1, BRCA2 und BRCA3
}

\section{Kiechle}

\section{Genetische Grundlagen \\ $\nabla$}

Das Risiko, an Brustkrebs zu erkranken, beträgt bei Frauen in Deutschland bis zum 70.Lebensjahr bei unbelasteter Familienanamnese etwa $10 \%$. In etwa 5\% aller Brustkrebsfälle handelt es sich um eine genetische vererbbare Form, bei der eine Veränderung im Genom der Patientin die Ursache der Erkrankung ist.

In etwa 50\% aller hereditären Mammakarzinome lassen sich heterozygote Mutationen in den autosomal-dominant vererbten Genen BRCA1 („breast cancer gene“) oder BRCA2 nachweisen. Ungefähr 5\% stehen im Zusammenhang mit Mammakarzinomassoziierten Syndromen. Für die restlichen $45 \%$ ist der genaue genetische Hintergrund bisher unbekannt. Es werden u.a. kombiniert polygene Varianten verantwortlich gemacht, oder es lassen sich seltene Mutationen in niedrig penetranten Genen wie ATM, CHEK2, BRIP1 und PALB2 nachweisen [1,2].

Im April 2010 haben deutsche Wissenschaftler jedoch entscheidend zur weiteren Aufklärung der genetischen Ursachen des hereditären Mamma- und Ovarialkarzinoms durch die Entdeckung eines weiteren hoch penetranten Gens beigetragen: RAD51C oder BRCA3. Pathogene Mutationen wurden in 480 BRCA1- und BRCA2negativen Individuen aus Familien mit erblichen Mamma- und Ovarialkarzinomen nachgewiesen. Dies entspricht einer Inzidenz von ca. 2\%. Bei reinen, hereditären, BRCA1- und -2-negativen Mammakarzinomfamilien wurden BRCA3-Mutationen allerdings sehr viel seltener, lediglich in $0,3 \%$, nachgewiesen [3].

Interessanterweise spielen alle bislang entdeckten Brustkrebsgene, sowohl die Gene BRCA1, BRCA2 und BRCA3, mit hoher Penetranz als auch die Gene ATM, CHK2, BRIP1 und PALB2 mit intermediärer Penetranz eine essentielle Rolle in der genomischen Stabilität von Zellen und sind an DNA Reparaturvorgängen beteiligt (D Abb.1).

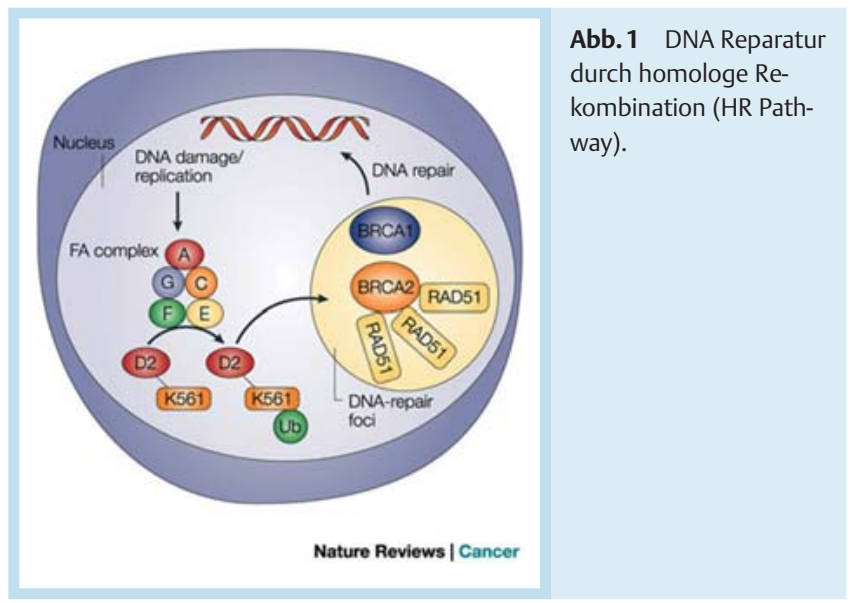

\section{Krebserkrankungsrisiken \\ $\nabla$}

Frauen mit einer Mutation auf dem BRCA1-Gen haben ein bis zu $80 \%$ iges Risiko, im Laufe ihres Lebens an Brustkrebs zu erkranken. Die Wahrscheinlichkeit, an Eierstockkrebs zu erkranken, liegt bei ca. 45-65\%. Bei einer BRCA2-Mutation liegt die Erkrankungswahrscheinlichkeit bei ca. 70\% für das Mammakarzinom und ca. 20-30\% für das Ovarialkarzinom.

Keimbahnmutationen im BRCA2-Gen gehen auch mit einem erhöhten Risiko für eine Brustkrebserkrankung beim Mann einher. Das Risiko für Kolon- und Prostatakarzinom ist gleichfalls erhöht. Eine moderate Risikoerhöhung wurde auch für Pankreas-, Zervix-, und Larynxkarzinome beobachtet.

Auch beim neu entdeckten BRCA3-Gen sind die Krebserkrankungsrisiken bei Mutationsträgerinnen ähnlich hoch. Das lebenslange Risiko liegt für das Mammakarzinom bei 60-80\% und für das Ovarialkarzinom bei 20-40\% ( Tab. 1).

Tab. 1 Krebserkrankungsrisiken von BRCA-Mutationsträgerinnen.

$\begin{array}{llll}\text { Krebsart } & \text { BRCA1 } & \text { BRCA2 } & \text { BRCA3 } \\ \begin{array}{l}\text { Mammakarzinom } \\ \text { Frauen }\end{array} & 80 \% & 70 \% & 60-80 \% \\ \text { Männer } & - & 6 \% & - \\ \text { Ovarialkarzinom } & 45-65 \% & 20-30 \% & 20-40 \% \\ \text { Prostata } & 15 \% & 20 \% & ? \\ \text { andere Karzinome } & \text { erhöht } & \text { erhöht } & ?\end{array}$

Im Vergleich zur Normalbevölkerung ist das lebenslange Risiko für Brustkrebs rund 10-fach, für Eierstockkrebs zwischen 15und 40-fach erhöht.

\section{Literatur}

1 Kiechle M, Meindl A. Das familiäre Mamma- und Ovarialkarzinom. Geburtsh Frauenheilk 2006; 66: 1-4

2 German Consortium for Hereditary Breast and Ovarian Cancer. Comprehensive analysis of 989 patients with breast or ovarian cancer provides BRCA1 and BRCA2 mutation profiles and frequencies fort he German population. Int J Cancer 2002; 97: 472 - 480

3 Meindl A, Hellebrand H, Wiek C et al. Germline mutations in breast and ovarian cancer pedigrees establish RAD51C as a human cancer susceptibility gene. Nat Genet 2010; 42: 410-414

Bibliografie

DOI http://dx.doi.org/10.1055/s-0031-1271518

Senologie 2011; 8: 103

(c) Georg Thieme Verlag KG Stuttgart · New York · ISSN 1611-6453

\section{Korrespondenzadresse}

Prof. Dr. Marion Kiechle

Ärztliche Direktorin der Frauenklinik

Technische Universität München · Klinikum Rechts der Isar Ismaninger Straße 22

81675 München

marion.kiechle@|rz.tu-muenchen.de 